\title{
ANALYSES OF BUILDINGS WITH BASE-TO-RIDGE POSTS IN THE NORTHERN PART OF MESOAMERICA
}

\author{
E. KOSHI, T. TSUCHIMOTO \& Y. LI \\ Interdisciplinary Graduate School of Science and Technology, Shinshu University, Japan.
}

\begin{abstract}
The objective of our project is to clarify the patterns of inheritance and the dissemination of wooden construction technologies on a global scale. For this objective, we took base-to-ridge posts in the northern Mesoamerica region as a sample of wooden construction. We analysed the characteristics of them and explored what those characteristics suggest in the context of inheritance and dissemination. The term 'base-to-ridge posts' here refers to posts that rise from the ground to provide direct support of the ridge. Mesoamerica is an important region in understanding the architectural history and traditions of Native Americans. In 2013, the authors conducted a field study on buildings with base-to-ridge posts in several countries in the northern part of Mesoamerica (Mexico, Guatemala and Belize) in order to obtain broader knowledge of the buildings in the region. The field study consisted of the following: (1) visual observation of buildings from the window of moving cars; (2) close observation and photography; (3) actual measurements; and (4) interviews.

We analysed the details of these 24 buildings according to the indices we set. As a result, we obtained a representative model of these 24 buildings and identified the following traits: gabled roof; non-natural roof material; without mortises; earth-fast posts; round, unpeeled logs with y-shaped tops; ridge-supporting posts consisting solely of base-to-ridge posts; three base-to-ridge posts; used as a shed; agricultural occupation; built by non-specialists; and built in or after 2000. We found that, among the twelve factors we identified as typical traits of the buildings with base-to-ridge posts in the area, as many as six reflected rudimentary technologies or were related to older lifestyles. Thus, as this representative model with its traits shows, buildings with base-to-ridge posts preserve many old architectural characteristics with simple appearances that are easy to recognize and are easy to build without professional techniques to be handed over from generation to generation.

Because of these characteristics, knowledge of buildings with base-to-ridge posts is easy to transmit and has the inherent power to spread. This power is based on the basic structure of this architectural style that can be learned by visual observation. The buildings with base-to-ridge posts in the northern part of the Mesoamerica region preserve the old techniques while being inherited, spreading, built, and maintained - they are an 'active architectural heritage' alive and practised today.
\end{abstract}

Keywords: actual field study, base-to-ridge post, Belize, dissemination, Guatemala, earth-fast post, inheritance, Mesoamerica, Mexico.

\section{INTRODUCTION}

Architectural traditions with old roots typically originate in the works of individuals, which are shared later in society as part of culture, inherited and disseminated thereafter. Existing structures of heritage value are the result and are a part of this establishment process. Those structures should be preserved and inherited as an active part of culture and history.

The objective of our project is to clarify the patterns of inheritance and dissemination of wooden construction technologies in the global scale. To approach this objective, this article reports on buildings with base-to-ridge posts. The function of those posts is simple and relatively easy to grasp for the entire picture of buildings that make use of them. A base-toridge post rises from the ground to directly support the ridge. A building with base-to-ridge posts has at least one base-to-ridge post. It has been reported that buildings with base-toridge posts have survived and exist globally (Giancarlo [1], and Tsuchimoto [2]), having been found in diverse areas including Africa (Umesao [3]), Europe (Schilli [4], Weiss [5], 
Gschwend [6], and Ota [7]), and Asia (Ivanov [8], Wakabayashi [9], Li and Tsuchimoto [10] and Watanabe [21]).

The buildings we studied in this article are located in the northern part of the Mesoamerica region; the region was a passing point for ancient humans when they migrated from the Eurasia continent to the South American continent through the North American continent. On the other hand, buildings with base-to-ridge posts are also found in isolated islands on the Pacific. Thus, the two possible routes of dissemination are via land and via sea. Regarding the dissemination routes, Hitoshi Watanabe, an anthropologist, lists the possible routes as follows: the first route via the Bering Strait (when it was land); the second along the shores of the northern Pacific Ocean (including the Aleutian Islands); and the third across the Pacific Ocean (Watanabe [11]). Bernard Wood, another anthropologist, claims that the third route should be across the Atlantic, not across the Pacific Ocean (Wood [12]).

The northern Mesoamerica region is important in understanding the history, traditions, inheritance and the methods of transmission of the architectural culture of Native Americans. Additionally, existing buildings with base-to-ridge posts should be preserved for the future because they are valuable parts of the heritage of Native Americans.

We found buildings with base-to-ridge posts in Jalisco State of Mexico in November 2012 (Koshi and Tsuchimoto [13], Fig. 1); consequently, we reviewed the literature related to the northern part of Mesoamerica (Nabokov and Easton [14], Morales [15], Prieto [16], Francisco [17], Beatriz [18]), and in 2013 conducted a field study in Mexico, Guatemala and Belize in order to have a more extensive examination of the architectural structures in the area (Tanaka [23], Koshi and Tsuchimoto [24]).

For fifteen days, from 5 June to 19 June in 2013, we conducted a field study hiring guides and drivers. In this study, we examined buildings with base-to-ridge posts and observed the construction process of some structures. The study consisted of the following four elements: (1) visual observation from the window of a moving car, (2) close observation and photography, (3) actual measurement and (4) interviews. Based on the results, this article will clarify the detailed characteristics of buildings with base-to-ridge posts in the area, while examining the entire construction process. In addition, we will illustrate the value of the buildings as the architectural heritage.

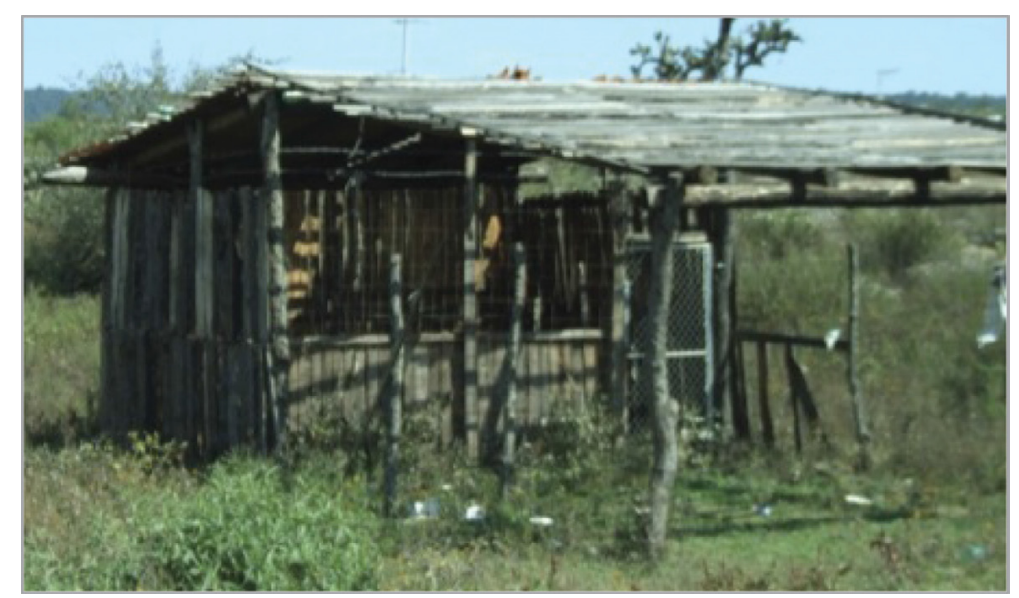

Figure 1: Building with base-to-ridge posts around Tapalpa in Jalisco State, Mexico, 2012. 


\section{BUILDINGS EXAMINED IN THE FIELD STUDY}

In this field study, we examined and photographed the buildings with base-to-ridge posts found by visual observation from the car window.

\subsection{Overview of studied buildings}

Among the 78 buildings we found promising, 41 buildings had base-to-ridge posts. We measured 24 buildings (Fig. 2 and Table 1) out of the 41 after obtaining the relevant permissions with the help of guides. Seven guides were hired for this field study. We managed to conduct interviews about 22 of the 24 buildings. Among these, the owner and the constructor of one building were not known (no. 21), but instead we interviewed the people living nearby.

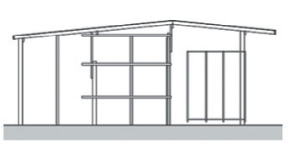

1 Unknown

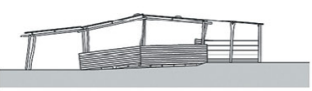

5 Ramos

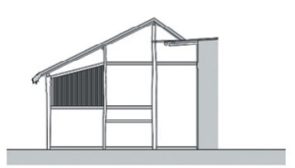

9 Lazaro

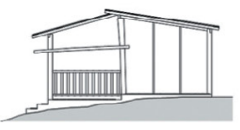

13 Santamaria

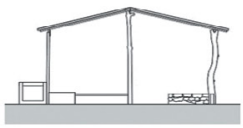

17 Hilario

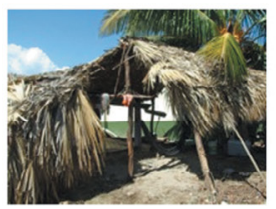

21 Unknown

Damaged by the last hurricane in May 2013.

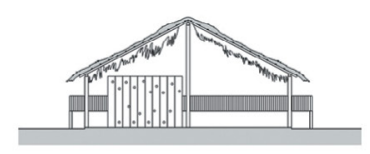

2 Cindy

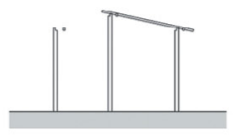

6 Lopiz

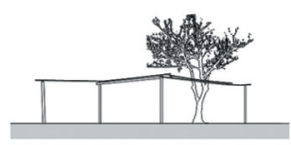

10 Orellana

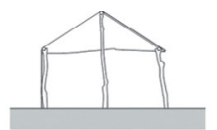

14 Rosa

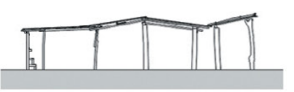

18 Teodomira

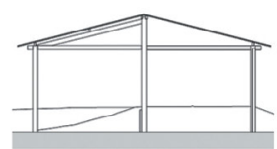

22 Pablo

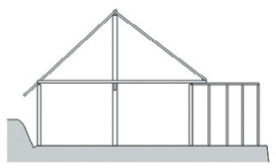

3 Albanil

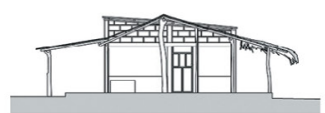

7 Rivas

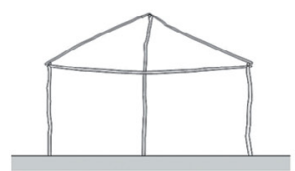

11 Roselin

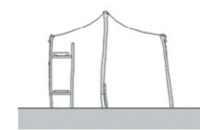

15 Mynor

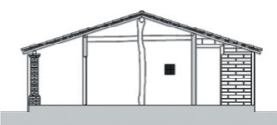

19 Pedro

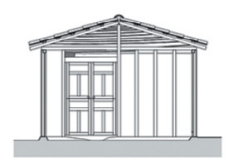

23 Lopez

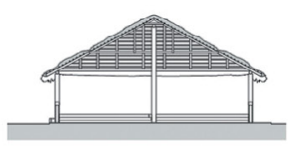

4 Unknown

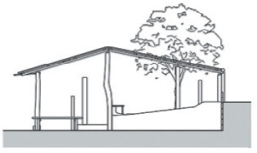

8 Humo
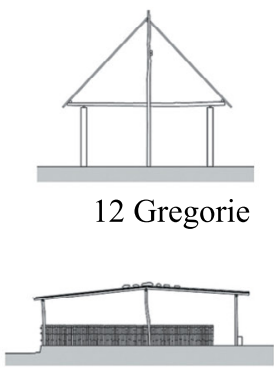

16 Macro

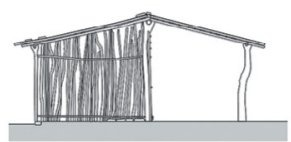

20 Daniela

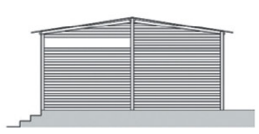

24 Mariano

Figure 2: Twenty-four buildings with base-to-ridge posts. 
Table 1: List of the measured buildings.

Table 1(a): No./Owner name/Location/Use/Constructor occupation

\begin{tabular}{|c|c|c|c|c|}
\hline No. ${ }^{1}$ & $\begin{array}{l}\text { Owner } \\
\text { name }\end{array}$ & Location & Use & $\begin{array}{l}\text { Constructor } \\
\text { occupation }\end{array}$ \\
\hline 1 & (Unknown) & Milpas Altas, Guatemala & Flower shop (shop) & (Unknown) \\
\hline $2+$ & Cindy & Agua Salobrega, Guatemala & Restaurant (shop) & Carpentry \\
\hline $\begin{array}{l}3+ \\
4\end{array}$ & $\begin{array}{l}\text { Albanil } \\
\text { (Unknown) }\end{array}$ & $\begin{array}{l}\text { Agua Salobrega, Guatemala } \\
\text { Agua Salobrega, Guatemala }\end{array}$ & $\begin{array}{l}\text { Restaurant (shop) } \\
\text { Restaurant (shop) }\end{array}$ & $\begin{array}{l}\text { Carpentry } \\
\text { (Unknown) }\end{array}$ \\
\hline $5+$ & Ramos & Tejerasan Jose, Guatemala & $\begin{array}{l}\text { Tile manufacturing } \\
\text { (shed) }\end{array}$ & $\begin{array}{l}\text { Tile } \\
\text { manufacturing }\end{array}$ \\
\hline $6+$ & Lopiz & Santa Barbara, Guatemala & Play space (shed) & (Unknown) \\
\hline $7+$ & Rivas & San Cristobal, Guatemala & Stable (shed) & Construction \\
\hline $8+$ & Humo & Rio Blanca, Guatemala & $\begin{array}{l}\text { Small bar-restaurant } \\
\text { (shop) }\end{array}$ & Agriculture \\
\hline $9+$ & Lazaro & Puerto Barrios, Guatemala & Resting place (shed) & (Unknown) \\
\hline $10+$ & Orellana & Puerto Barrios, Guatemala & Garage (shed) & House painting \\
\hline $11+$ & Roselin & Yemeri Grove, Belize & Shed & Agriculture \\
\hline $12+$ & Gregorie & San Antonio, Belize & Dwelling & Agriculture \\
\hline $13+$ & Santamaria & Cotton Tree, Belize & Shed & Catering \\
\hline $14+$ & Rosa & Zapote, Guatemala & Shed & (Unknown) \\
\hline $15+$ & Mynor & Zapote, Guatemala & Shed & (Unknown) \\
\hline $16+$ & Marco & Cuernavaca, Mexico & Shed & Agriculture \\
\hline $17+$ & Hilario & Lguala, Mexico & Dwelling & Agriculture \\
\hline $18+$ & Teodomira & Xalapa, Mexico & Fruit shop (shop) & Agriculture \\
\hline $19+$ & Pedro & Oaxaca, Mexico & Dwelling & Agriculture \\
\hline $20+$ & Daniela & Paredon, Mexico & Shed & Fishery \\
\hline $21+$ & (Unknown) & Paredon, Mexico & Shed & Fishery \\
\hline $22+$ & Pablo & Tenejapa, Mexico & Resting place (shed) & (Unknown) \\
\hline $23+$ & Lopez & Zinacantán, Mexico & Kitchen (shop) & Construction \\
\hline $24+$ & Mariano & Zinacantán, Mexico & General shop (shop) & (Unknown) \\
\hline
\end{tabular}

Note: 1 . Numbers are given in chronological order of study. An interview was conducted for the ones marked with plus signs (+). The owner of no. 21 was not known, but we interviewed people in the neighbourhood.

\subsection{Analysis of the measured buildings}

This article will analyse the 24 buildings that we measured (Fig. 2), according to the indices we set for showing major architectural characteristics.

2.2.1 Index 1: Roof shape - gabled or not

All of the 24 buildings had gabled roofs (24/24, 100\%). Still, in Mexico, some buildings with base-to-ridge posts have hip roofs, not gabled ones [16]. 


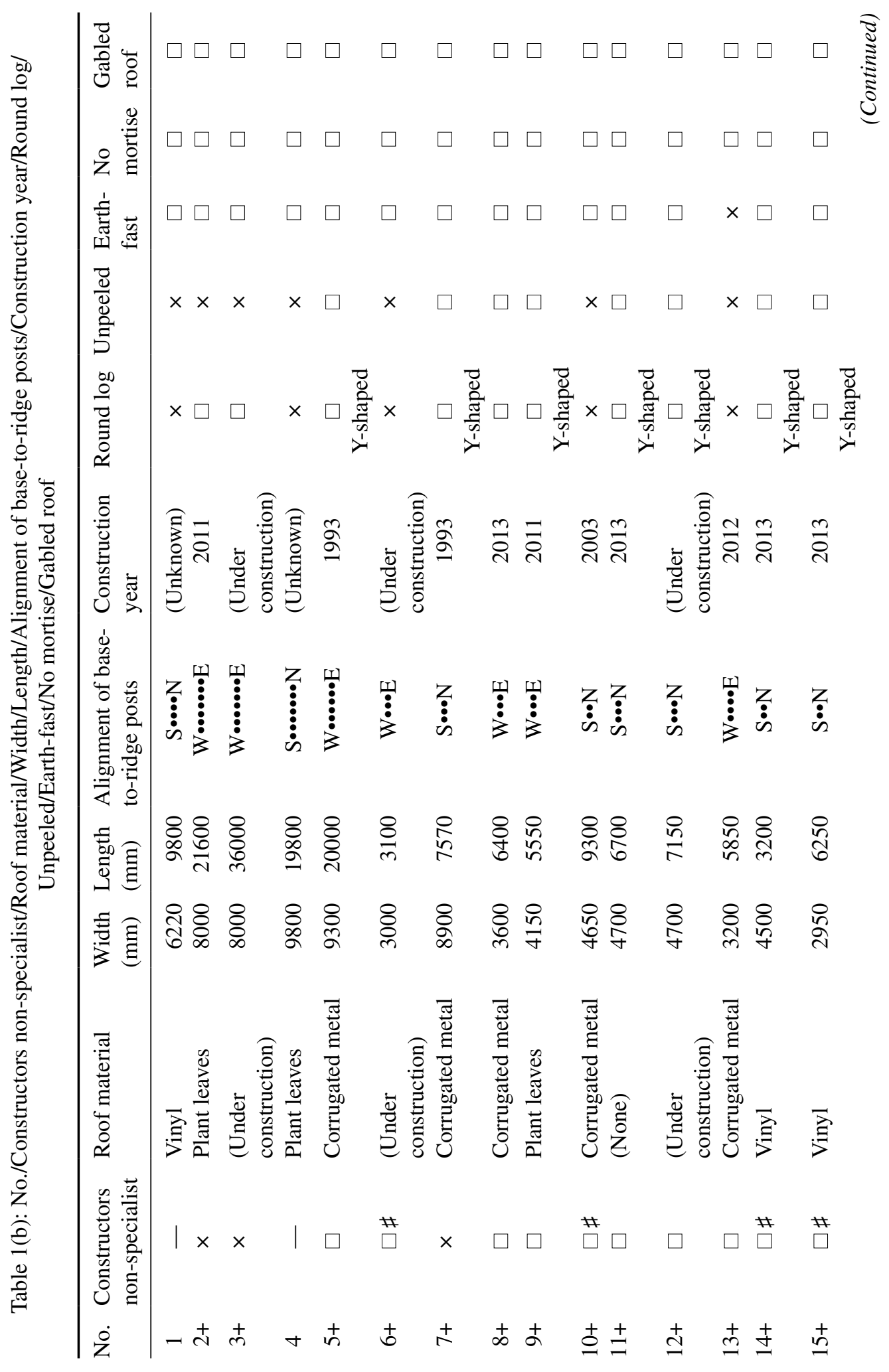




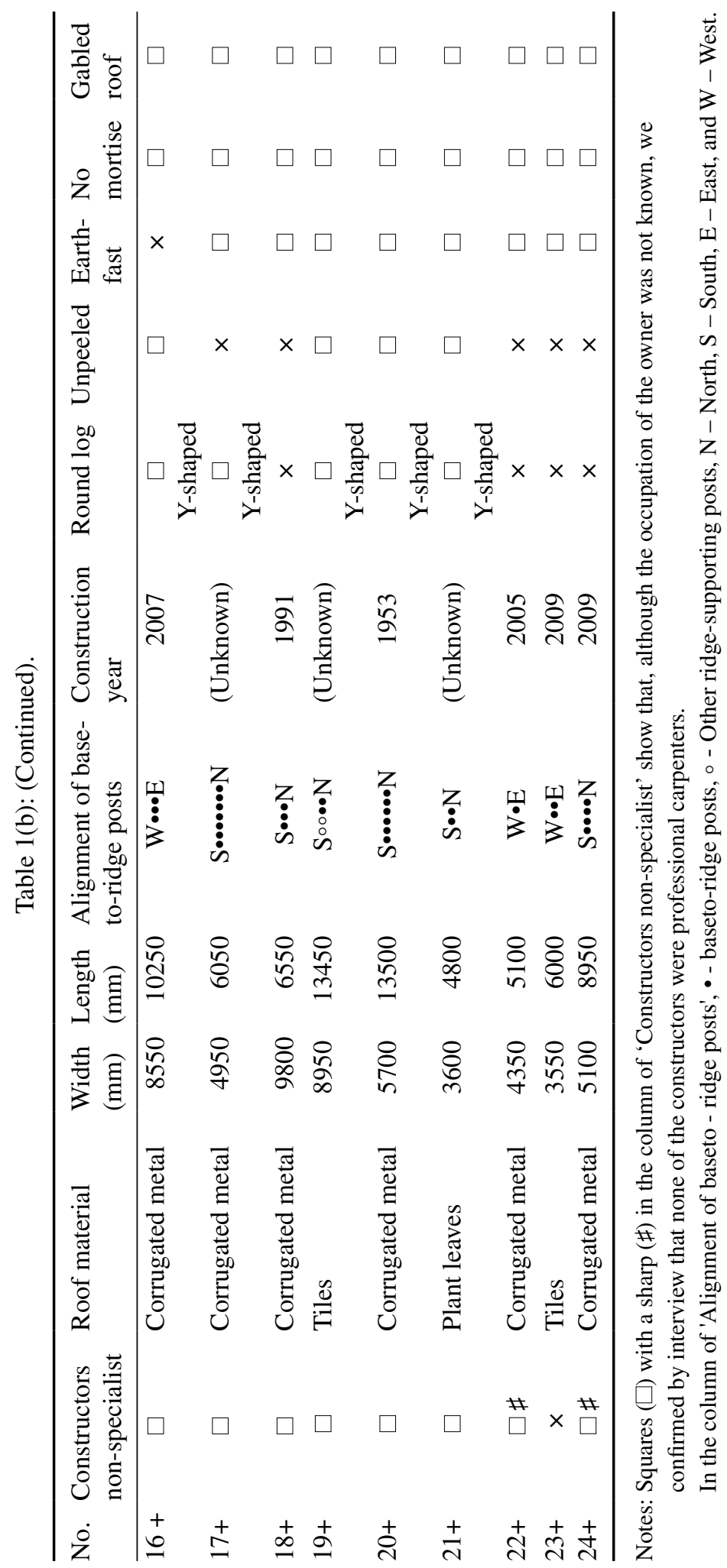




\subsubsection{Index 2: Roof material - natural or not}

Three buildings were under construction and their roofs were not built yet. As for the remaining 21 buildings, a variety of materials (Oliver [22]) were used for their roofs, which are listed as follows: corrugated metal for 11 buildings (11/21, 52.4\%); plants for 4 buildings (palm leaves, sedge, grass) $(4 / 21,19.0 \%)$; vinyl for 3 buildings $(3 / 21,14.3 \%)$; tiles for 2 buildings $(2 / 21,9.5 \%)$; no material for 1 building (the roof is on only when the building is used by people) $(1 / 21,4.8 \%)$. Non-natural materials were used in the majority of the buildings; the percentage of non-natural material (corrugated metal, vinyl and tiles) was $76.2 \%$ $(16 / 21)$ while that of natural material was $19.0 \%$ (4/21). Among the buildings using natural material, 4 (building nos. 2, 4, 9 and 21) were confirmed by interviews and visual observations while using the leaves of local palm plants. In Mexico, some buildings with base-toridge posts have reportedly used maguey leaves for the roofs [16].

\subsubsection{Index 3: Connection of base-to-ridge posts to horizontal timbers - with or without mortise}

All of the 24 buildings did not have mortise on base-to-ridge posts $(24 / 24,100 \%)$. Even in the cases where a base-to-ridge post and a horizontal timber intersected each other at right angles, they were only tied together with rope; there was no mortise on the post. Iron tools, such as chisels, and the advanced technology to use them are needed in order to make mortises.

2.2.4 Index 4: Bottom part of base-to-ridge post - earth-fast or not

In 22 buildings, the bottom of the base-to-ridge posts was directly buried in the ground $(22 / 24,91.7 \%)$.

\subsubsection{Index 5: Processing and finishing of base-to-ridge posts - log or not,} and with or without bark

The buildings were classified into those that used unprocessed round logs for base-to-ridge posts and those that used squared logs. Fifteen buildings used round logs $(15 / 24,62.5 \%)$.

Both unpeeled logs and peeled logs were used for base-to-ridge posts. Twelve buildings used posts with bark, sharing $50.0 \%$ of the measured 24 buildings (12/24), and $80.0 \%$ of the 15 buildings using round $\operatorname{logs}(12 / 15)$. The finished surface of the logs can be decided by the constructor's preference as typically shown in one comment obtained in the interviews: 'Bonito Así. Me gusta esto' (I like it better that way), describing the reason for leaving the logs unpeeled (no. 8).

\subsubsection{Index 6: Top part of base-to-ridge post - y-shaped or not}

Twelve buildings used base-to-ridge posts with y-shaped top (12/24, 50.0\%). Logs with $y$-shaped tops were difficult to find at present, as one person in the interviews stated as follows: 'It would be the best if I could use logs with natural y-shaped tops for all posts, but they are difficult to find, so I am making them myself by carving the top into that shape' (no. 9).

\subsubsection{Index 7: Weight of base-to-ridge posts - only base-to-ridge posts support the ridge or not}

The base-to-ridge posts were defined as posts that rose directly from the ground to support the ridge. Buildings with base-to-ridge posts have at least one base-to-ridge post. In this study, the authors determined whether all of the posts supporting the ridge were base-toridge posts for each of the buildings. The result was that for 23 buildings, all of the ridgesupporting posts were base-to-ridge posts $(23 / 24,95.8 \%)$. 
2.2.8 Index 8: Number of base-to-ridge posts

Each of the 23 buildings, at which all of the ridge-supporting posts were of the base-to-ridge type, had the following number of base-to-ridge posts: 1 building had 1 post $(1 / 23,4.3 \%)$, 5 buildings had 2 posts $(5 / 23,21.7 \%), 8$ buildings had 3 posts $(8 / 23,34.8 \%), 3$ buildings had 4 posts $(3 / 23,13.0 \%), 0$ building had 5 posts $(0 / 23,0.0 \%), 2$ buildings had 6 posts $(2 / 23$, $8.7 \%), 4$ buildings had 7 posts $(4 / 23,17.4 \%)$.

Three base-to-ridge posts were used by the greatest number of buildings at 8 buildings $(34.8 \%)$. A building with 3 base-to-ridge posts could maintain the square shape. Hence, there was the possibility that buildings with 3 base-to-ridge posts evolved from the square-shaped buildings (Schmidt [19]). However, this study did not establish that this possibility was actually the case.

\subsubsection{Index 9: Use of the buildings}

Thirteen of the buildings were used as sheds $(13 / 24,54.2 \%), 8$ buildings were used as shops $(8 / 24,33.3 \%)$, and 3 buildings were used as houses $(3 / 24,12.5 \%)$. The 13 buildings used as sheds had other functions, including play spaces for children and resting or workplaces with shade for fishermen. The buildings used as shops included a fruit shop and a small barrestaurant; notably, one large-scale restaurant was under construction (no. 3, Fig. 3).

\subsection{Analysis of the 21 buildings about which interviews were conducted}

This article will analyse the 21 buildings about which interviews were conducted.

\subsubsection{Index 10: Occupation of the constructors}

Among the 24 measured buildings, the constructor was unidentified for 8 of them (6 were with interviews, 2 were not). As for the remaining 16 buildings, we identified the major occupations of their constructors as follows: agriculture: 7 buildings $(7 / 16,43.8 \%)$; carpentry and construction: 4 buildings $(4 / 16,25.0 \%)$; tile manufacturing and painting (car painting): 2 buildings (2/16, $12.5 \%)$; fishery: 2 buildings $(2 / 16,12.5 \%)$; and catering: 1 building (1/16,
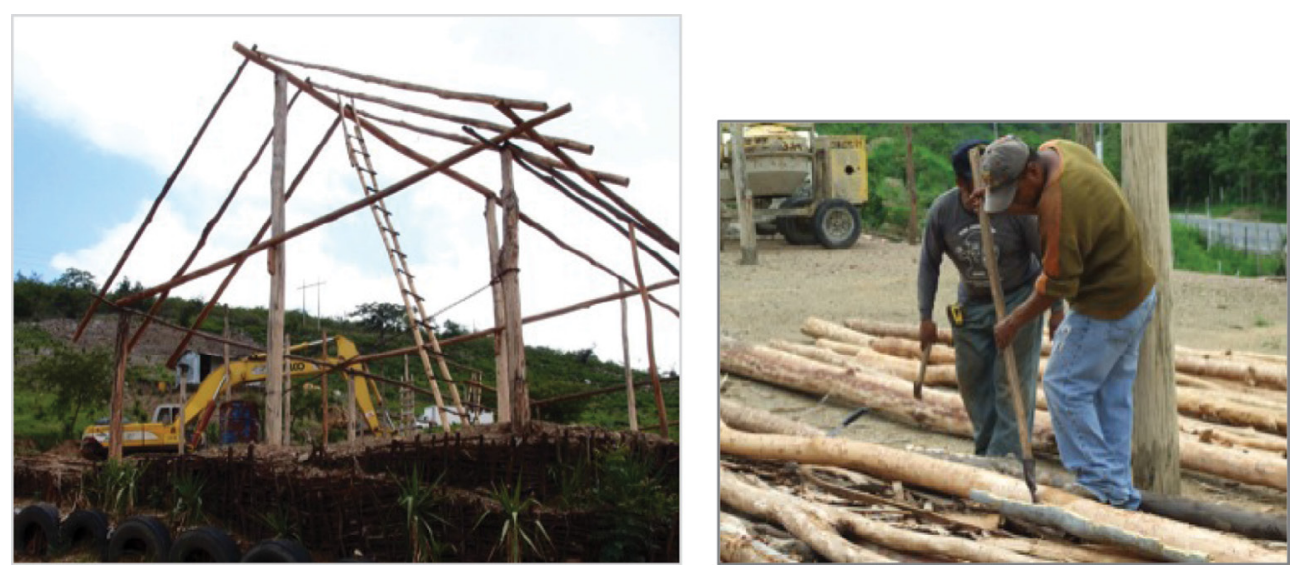

Figure 3: Appearance of no. 3 with base-to-ridge posts and its constructor peeling of eucalypti in Agua Salobrega, Guatemala, 2013. 

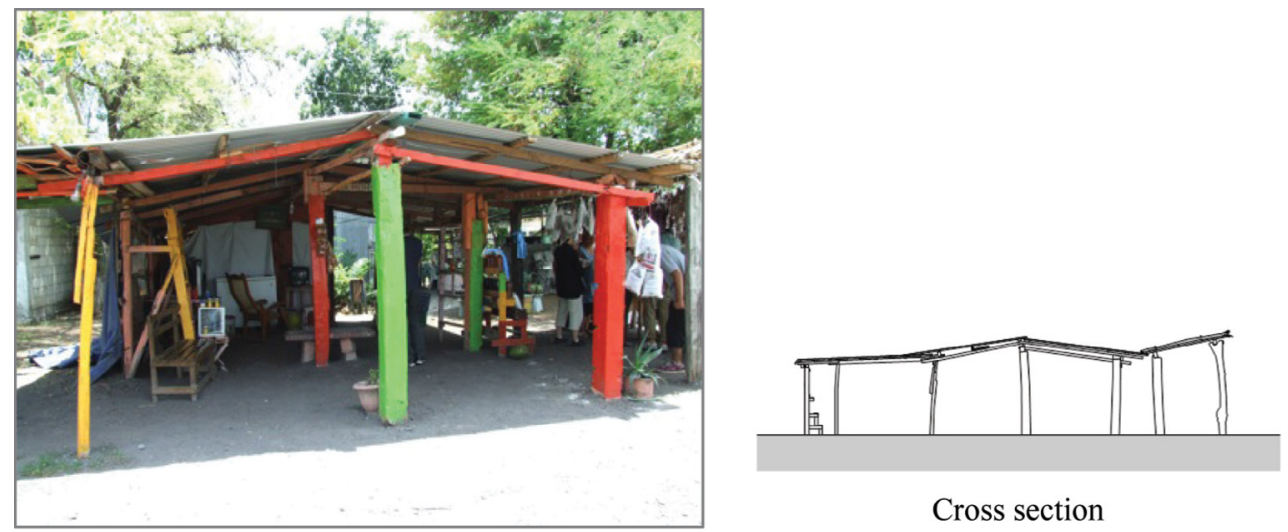

Figure 4: Appearance of no. 18 with base-to-ridge posts in Xalapa, Mexico, 2013.

$6.3 \%) .68 .8 \%(11 / 16)$ of all the constructors did not have specialist knowledge of the construction.

One of the significant factors in the construction that was discovered during the interviews was that some building construction was based on the experience of the constructors helping with other construction work (nos. 8, 9, 17 and 19) or on previous observation of buildings with base-to-ridge posts from moving cars (nos. 3 and 16). In most cases, the owner of the building was the constructor, who did the work with the cooperation of friends or other people (18 buildings, such as no. 10). Furthermore, posts were painted in vivid colours in the process of maintenance in one case (no. 18, and Fig. 4). The reason for the use of such colour was that, according to the interview, the colour was the preference of the wife of the owner. This case shows that the appearance of buildings can change over time due to the preferences of owners or those close to them.

\subsubsection{Index 11: Constructors - specialist or not}

Among the 21 buildings about which we conducted interviews, 18 were built by the owner, friends and/or family $(18 / 22,81.8 \%)$. This indicates that most of the constructors were not specialists.

\subsubsection{Index 12: Year of production}

We obtained the year of production for 19 buildings. Among the 19 buildings, the focus was on the oldest ones and the newest ones. The oldest building was built in 1953 (no. 20), while the newest buildings were those under construction during this study (nos. 3, 6 and 12).

The time of production ranged over more than half a century from one built sixty years ago to ones under construction. Also, among the 19 buildings whose years of production were known, 15 buildings were built during or after 2000 (15/19, 78.9\% including the ones under construction), showing that buildings with base-to-ridge posts are still being built and used actively.

\section{FACTORS WITH THE LARGEST SHARE FOR THE INDICES}

The factors with the largest share for the indices listed thus far were as follows: for index 1: gabled roof, $100 \%$ of the whole (24/24); index 2: non-natural roof material, $66.7 \%$ of the whole (16/24); index 3: without mortise, $100 \%$ of the whole (24/24); index 4: earth-fast style, 


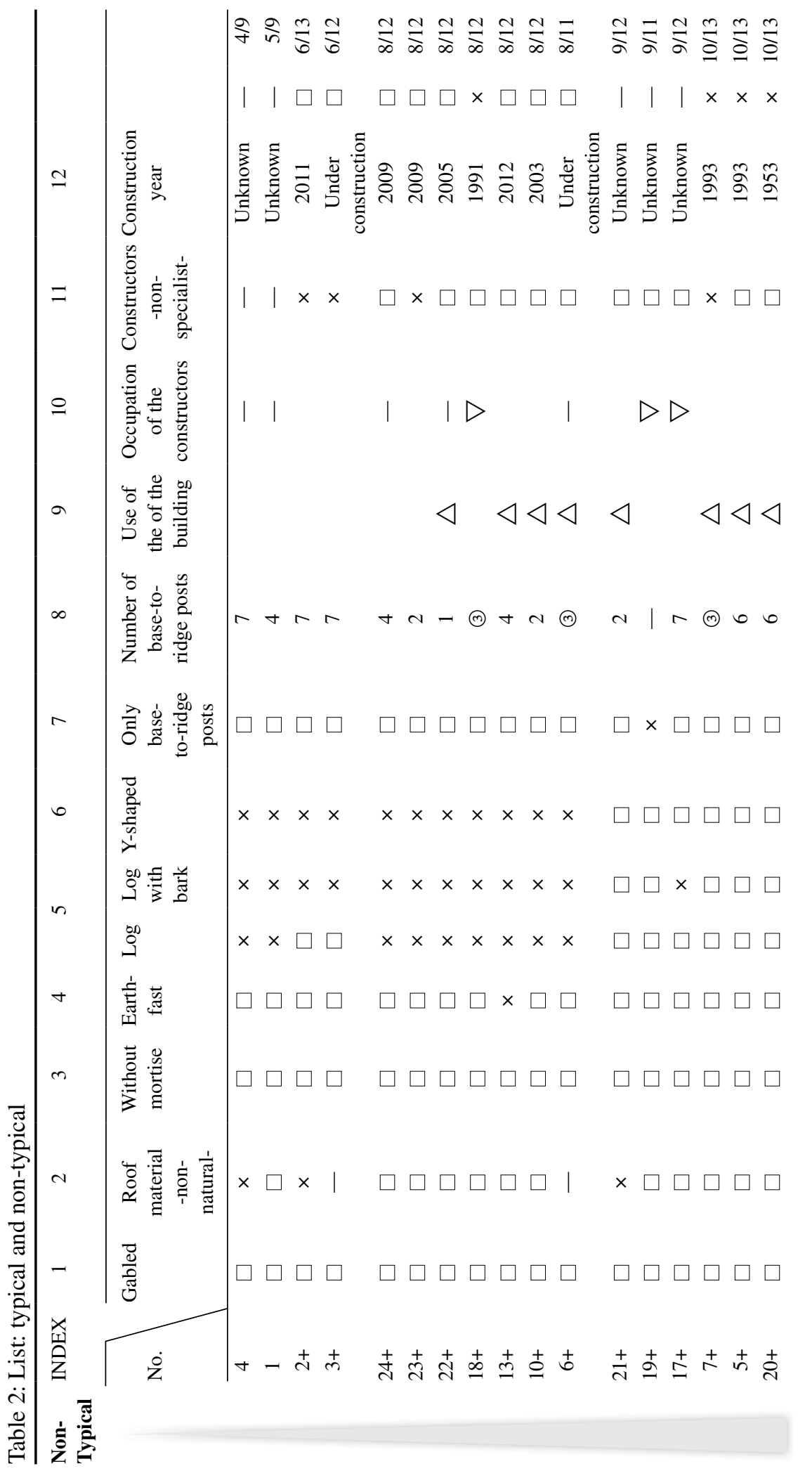


$\stackrel{m}{\rightrightarrows} \stackrel{m}{\Xi} \stackrel{m}{\Xi} \stackrel{m}{\Xi} \stackrel{m}{a}$

$\neg \square \square \quad \square \square \square \square \stackrel{\vartheta}{\mathrm{s}}$

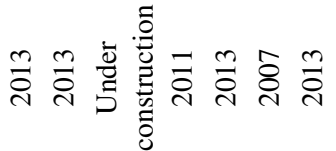

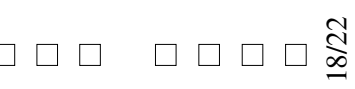

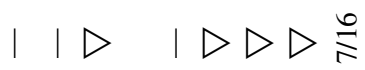

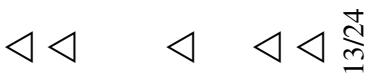

$44 \rightarrow(-) \rightarrow \infty)+\frac{\pi}{3}$

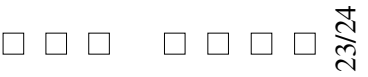

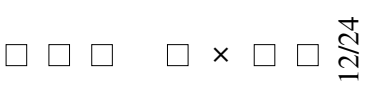

$\square \square \square \quad \square \square \square \square \stackrel{\text { ป }}{\beth}$

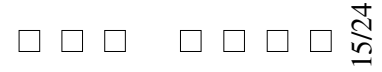

$\square \square \square \quad \square \quad \square \times \stackrel{\text { त }}{\text { त }}$

$\square \square \square \quad \square \quad \square \quad \frac{\text { 辛 }}{\stackrel{4}{4}}$

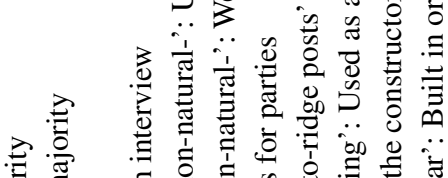

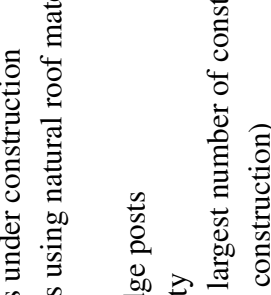

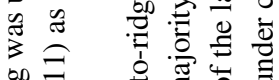

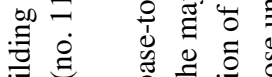

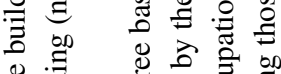

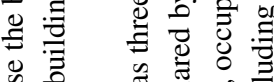

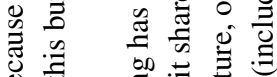

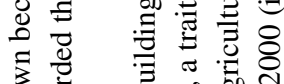

政言

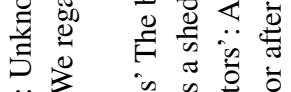

鄫

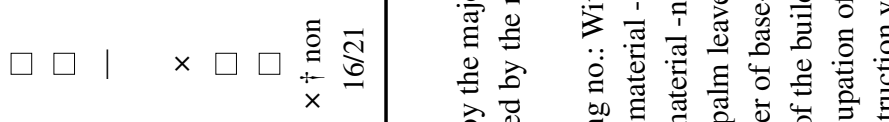

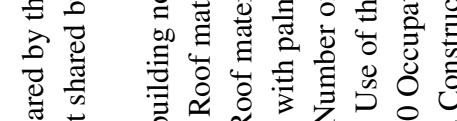

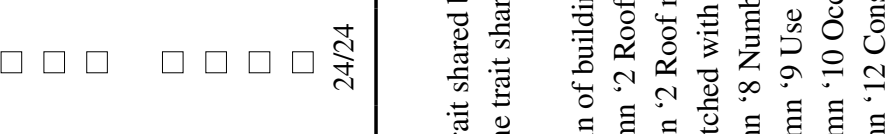

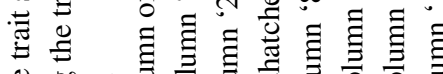

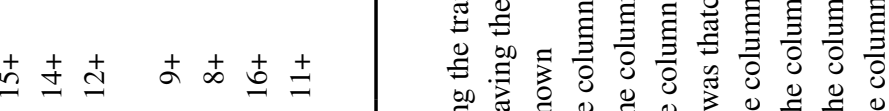

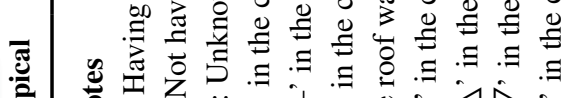

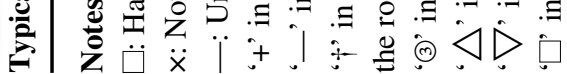


$91.7 \%$ of the whole $(22 / 24)$; index 5 : round $\operatorname{logs}, 62.5 \%$ of the whole $(15 / 24)$; among the 15 cases with round $\operatorname{logs}, 80.0 \%$ were using the logs unpeeled $(12 / 15)$; index 6 : posts with y-shaped top part, $50.0 \%$ of the whole $(12 / 24)$; index 7 : base-to-ridge posts consist all of ridge-supporting posts, $95.8 \%$ of the whole (23/24); index 8: among those 23 cases in which base-to-ridge posts all consist of ridge-supporting posts, the most common number of baseto-ridge posts was 3 , or $34.9 \%$ of the whole (8/23); index 9: the use of building was as a shed, $54.2 \%$ of the whole (13/24); index 10: among 16 cases in which the constructor's occupation was known, agriculture was the major occupation in $43.8 \%$ (7/16), index 11: among 22 cases about which an interview was conducted, $81.8 \%$ were not specialists in construction (18/22); and index 12: among 19 cases about which the year of construction was known, the majority of the buildings were built after 2000 (including those under construction), $62.5 \%$ of the whole $(15 / 24)$.

\section{PERSPECTIVE ON REPRESENTATIVENESS}

Each index dichotomizes the sample buildings into ones with a trait shared by the largest number (most of the time the majority) and others without the trait.

The indices with two options, such as whether the base-to-ridge posts have mortises or not, dichotomize the sample buildings. For such indices, we consider the trait shared by the larger number as representative of all the samples regarding that index. Likewise for the indices with three or more options, such as the index about the use of the building, we can regard the trait shared by the larger number as representative and the others as non-representative. In the case of the use of the building, the trait 'use as a shed' is shared by the largest number of buildings and is therefore the representative trait, while all the other traits are considered not validly representing all the buildings. Thus, the index about the use of the building dichotomizes the sample buildings, those with the most representative trait (the ones used as a shed) and those without it (the others not used as a shed). In this manner, each index dichotomizes the buildings surveyed.

Based on this dichotomization, we interpreted buildings with base-to-ridge posts that had a larger number of traits listed above as more representative of the whole and those with a smaller number of those traits as less representative. With these criteria, the most representative buildings of the ones we studied were nos. 11 (Fig. 5) and 16 (with a gabled roof, without
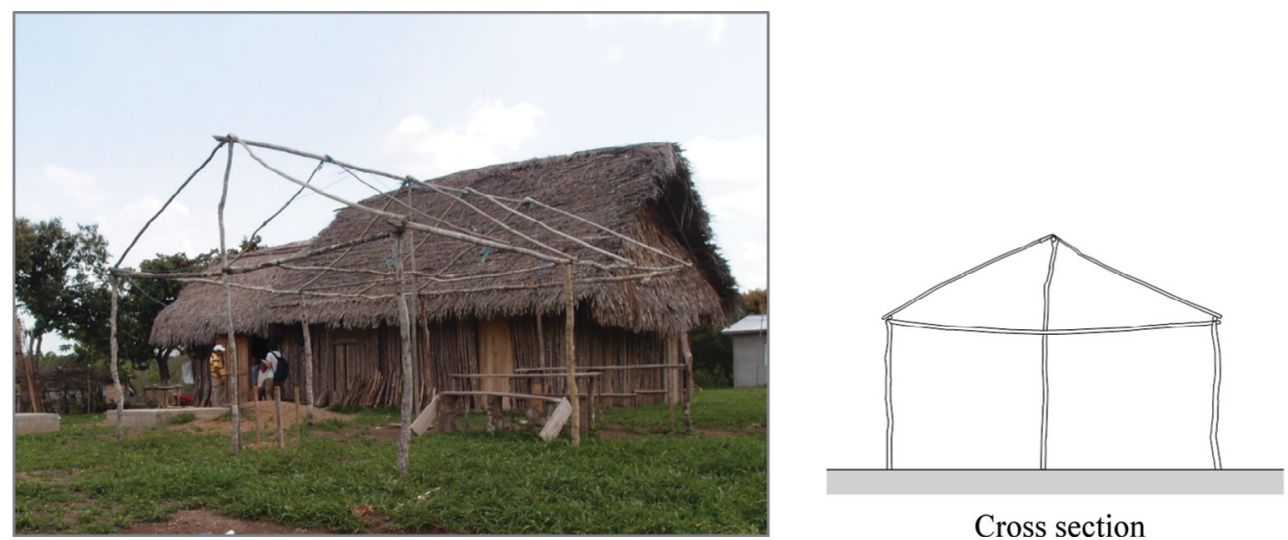

We learned from interviews that the roof of this structure was thatched with palm leaves for parties.

Figure 5: Appearance of no. 11 with base-to-ridge posts in Yemeri Grove, Belize, 2013. 
mortises, round logs, unpeeled, y-shaped top, base-to-ridge posts consisting all of the posts, 3 base-to-ridge posts, used as a shed, agricultural occupation, built by non-specialist, and built in or after 2000). No. 16 used non-natural roof material, while no. 11 used a natural material (we discovered during an interview that the roof was thatched with palm leaves for parties). The base-to-ridge posts of no. 11 are earth-fast, and those of no. 16 are not. On the other hand, the least representative building identified was no. 4, which had the fewest number of common traits (with a gabled roof, without mortise, earth-fast posts, base-to-ridge posts consisting all of the posts).

\section{OBSERVATIONS ON AGE}

Some of the indices used in this analysis can be understood as indicating the age of the technology used for the building. We identified the following traits as the criteria for age: (s) the use of natural materials is older than that of non-natural ones; (t) the use of non-iron tools is older than that of iron ones; (u) the use of unprocessed posts is older than that of unprocessed ones; (v) the use of earth-fast posts is older than that of non-earth-fast ones; (w) the use of posts with y-shaped tops is older than the use of those with plain tops; (x) the use of ridgesupporting posts without gaps is older than the use of those with gaps; (y) construction by non-specialists is older than that by specialists; and (z) chronological age is shown by the year of production.

Thus, we listed the following as indices for older technology: natural material for the roof (s); lack of mortise on the base-to-ridge posts (t); unprocessed and unpeeled logs (u); the bottom of base-to-ridge posts buried directly in the ground (v); the y-shaped top of baseto-ridge posts $(\mathrm{w})$; base-to-ridge posts consisting of all the ridge-supporting posts (x); nonspecialist constructor (y); and the index for the age of the buildings built before 2000 (z). Accordingly, we regarded the opposite (i.e. complementary) of each of these traits as indices for newer technologies.

Some indices did not show the age of the technology, which were: whether the roof was gabled or not; the number of base-to-ridge posts; the occupation of owner; and the use of the building.

We made Table 3 to list the indices that show age only $(3,7,4,11,5 \mathrm{a}, 5 \mathrm{~b}, 6,12,2)$. ' $\square$ ' and ' $x$ ' in it are the same as in Table 2. ' $\square$ ' indicates the indices showing the age as old.

We can see from Table 2 that nos. 5, 9, 11 (Fig. 5), 20 (Fig. 6), and 21 have the largest number (eight) of traits of older technologies. Hence, we regard them as the best representations of
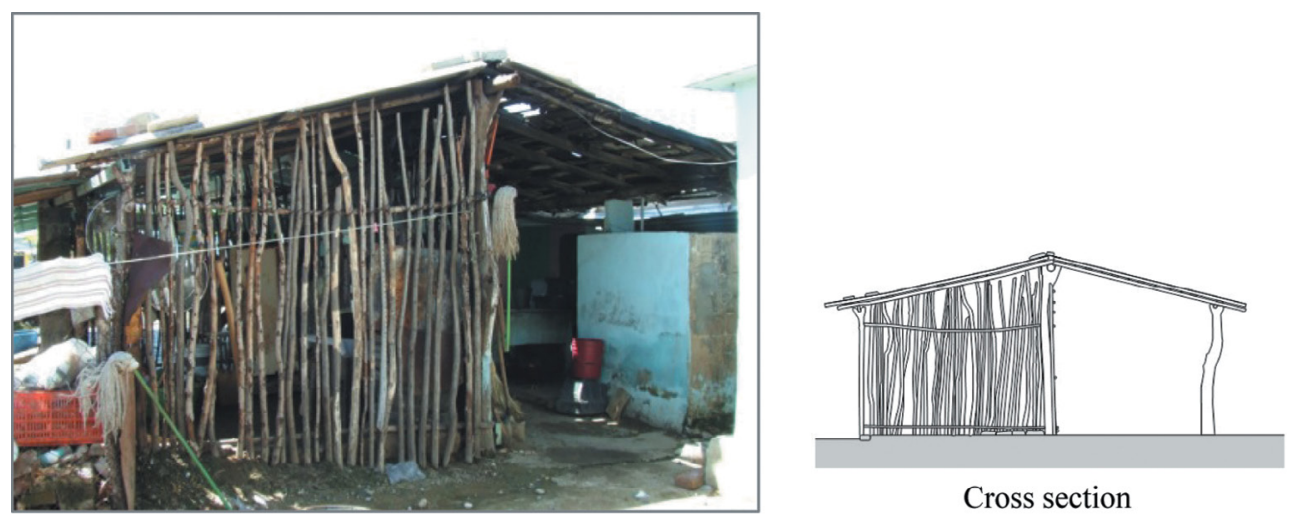

Figure 6: Appearance of no. 20 with base-to-ridge posts in Paredon, Mexico, 2013. 


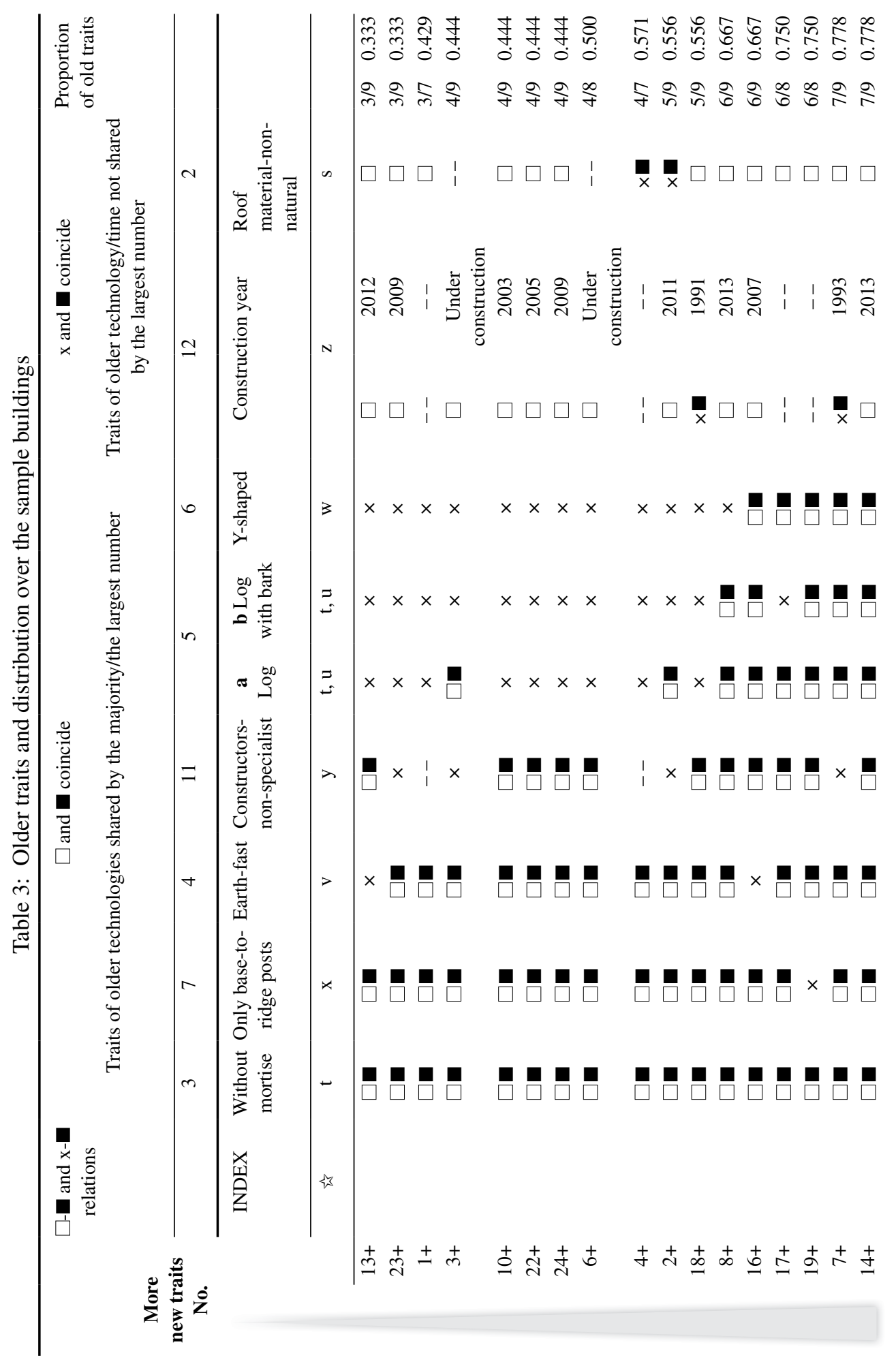




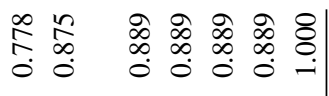

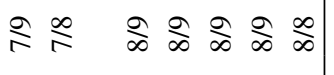

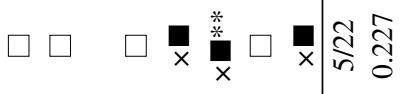

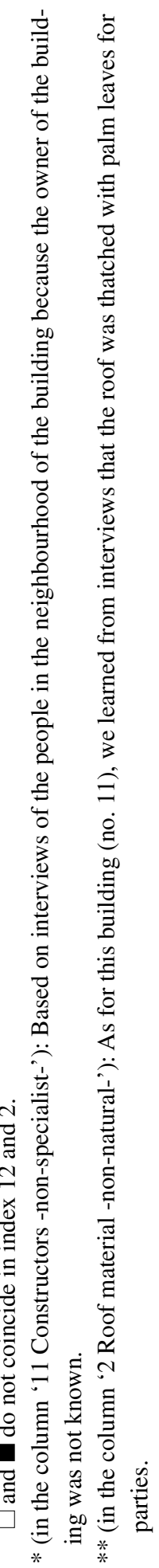


the older styles among the sample buildings. Especially, nos. 9, 11 and 21 have all of the traits of older technologies (except the production year). No. 9 was built in 2011, no. 11 in 2013, and no. 21 was unknown. Nos. 5 and 20 use non-natural material for the roofs, but have all the other traits. The year of production is 1993 for no. 5 and 1953 for 20. It is noteworthy that no. 20 was actually the oldest among all the buildings.

In contrast, the ones with only three of the old traits, viz. nos. 1, 13 and 23, incorporated many traits of newer technologies as part of their architectural structure.

Thus, among the buildings we surveyed, the ones with eight traits of older technologies are the most representative samples of old-style buildings with base-to-ridge posts, and those with three of such traits the least representative samples. We found that there were cases where typical buildings with base-to-ridge posts had all the traits of an old building except for the construction year, while there was one case in which a non-typical building preserved the traits, if just two, of an old building. It is particularly noteworthy that buildings with base-toridge posts with many old traits have still been built after 2000, showing that the old culture is being preserved.

Apart from that, of the two buildings (nos. 11 and 16) we identified based on Table 2 as most representative of all the surveyed characteristics of the sample buildings, no. 11 has eight traits of older technologies while no. 16 has six. On the other hand, no. 4, the one identified from Table 2 as least representative of the average characteristics, still retains four traits of older technologies.

No. 11 was built as recent as 2013 , while being the most representative of the older technologies with eight traits of all the surveyed characteristics. It is noteworthy that the buildings with older traits, such as no. 11, were built after 2000. In addition, no. 20, another representative sample of older technologies with eight of the indicative traits, was built as early as 1953 in contrast with no. 11. No. 20 is actually the oldest sample of the surveyed twenty-four buildings. The co-presence of nos. 11 and 20 strongly suggests that the traditional architectural culture of this region has been actively preserved.

\section{INHERITANCE AND DISSEMINATION}

In the northern part of Mesoamerica (Mexico, Guatemala and Belize) today, a large number of buildings with base-to-ridge posts exist. From the 24 buildings measured, a number of characteristics were extracted that demonstrated the simple nature of the style, including the use of unpeeled round logs, y-shaped top, earth-fast bottom and natural roof materials. Note, however, that as primitive as they are, those buildings were complete on their own as architectural structures with benefits of being hurricane-resistant probably selected as part of the effective knowledge for survival. In addition, most of those buildings were built by the people whose major occupations were agriculture or fishery. Buildings with base-to-ridge posts were chosen intentionally by the non-specialist constructors because they had the advantage of being easy to build and were structurally stable.

Furthermore, those buildings were often built by the owner with the cooperation of friends and family. From this fact, the technology of buildings with base-to-ridge posts was preserved through the cooperation of the local communities in building this type of building. There were also cases where the constructor built the structure based on a memory of the same type of building he had seen on the road from a passing car (nos. 3 and 16). The constructor of no. 3 (Fig. 3) was a professional carpenter, while that of no. 16 was a farmer, not a specialist in construction.

The observations described thus far indicated that the buildings with base-to-ridge posts were still in use and inherited by the people in the area because their structure could be 
learned simply by looking, and they could be built without direct training from predecessors. In addition, the structure with base-to-ridge posts has functional advantages that suit not only hurricane-prone areas, but also other areas with different climate conditions. As such, this structure continues to be actively selected today in a wide range of areas. Also, two contrasting tendencies exist among those who make or own such buildings: one is to preserve the old architectural structure as it has been, and the other is to make changes on buildings' appearance.

Not everything old can survive, and those that have survived have reasons for the survival. Buildings with base-to-ridge posts, which already existed in ancient times, survived, and were inherited up to the present because of very simple and plain construction in comparison with other old buildings, in the sense that the building structure can be understood even by a single observation. The form of the building with this structure is easy to remember as a visual image, and this image is easy to be made into a real building. Because of these factors, buildings with base-to-ridge posts are still being built today, while preserving their old traits.

\section{OBSERVATIONS ON THE TREE SPECIES}

Now we discuss the fact that some parts of an architectural tradition can be replaced over time with the tree species used for the buildings we surveyed as an example. We found, for instance, from close observation and an interview that eucalyptus is used as the post material for no. 3 (Fig. 3). At the construction site of this building, we obtained a positive comment about this choice of material from the constructor.

We regard the buildings with base-to-ridge posts being built and used in the northern part of the Mesoamerica region as part of an active architectural heritage. From this perspective, the use of eucalyptus, an alien species to the region, can be seen as both detrimental and not detrimental depending on which aspect of the tradition we focus on (detrimental in the sense that it is a change to tradition, and non-detrimental in the sense that it helps the tradition continue). Thus, we will explain the two aspects of how architectural heritages survive: the first aspect is introducing new elements and the second aspect is preserving existing ones.

Some elements of an architectural tradition are sustained by adopting alien materials and technologies. In contrast, other elements need to preserve materials, technologies, forms and scale inherited from previous generations. We claim that both form an active architectural heritage.

Changes in the materials and technologies often occur during the dissemination of architectural traditions, while preservation occurs when a tradition is inherited within the same cultural framework. In the case of the buildings with base-to-ridge posts in the Mesoamerica region, the architectural form and structure have been preserved by finding and using the most suitable materials available, rather than the fact that the architectural form and structure have adapted to the available tree species. The use of eucalyptus for buildings with base-toridge posts in Mesoamerica is a case in which part of the materials have been replaced by alien species while the structure with base-to-ridge posts is preserved.

The concept of active architectural heritage means that architectural traditions for buildings with base-to-ridge posts can disseminate by altering some materials but preserving the same structure.

Architectural heritages of this type sometimes alter the materials in order to help preserve the structure. For example, new materials may be used when the environment has changed rapidly and previously used materials are no longer available. In addition, there are cases in which the structure of buildings with base-to-ridge posts has suited well the environment of 
new areas. The applicability to different environments contributed to the survival and spread of this type of architectural heritage. Still, there are other buildings of the same type that allow traditional materials only, which we would call active architectural heritages as well, as long as they are inherited and used as part of everyday lives.

\section{INHERITANCE AND DISSEMINATION OF ACTIVE ARCHITECTURAL HERITAGES}

Next, we examine the broader context of inheritance and the dissemination of buildings with base-to-ridge posts. Buildings with base-to-ridge posts discussed in this article are a rudimentary type of architecture and found in disparate locations. However, judging from the evolution of human civilization in general, we assume that it was not easy for humans to develop buildings with base-to-ridge posts as a complete and stable architectural structure. Although the structure with base-to-ridge posts is rudimentary, it must have taken a long period to fully develop as an architectural style. Nonetheless, once this architectural type was established, it was probably easy to inherit within the same region or disseminate to other regions. One issue is that it is very difficult to identify how and when this type of architecture was established. Hoping to pave the way for clarification of that issue, this article tried to capture how this type was inherited and disseminated through a field study.

It is reasonable to suppose that the development of buildings with base-to-ridge posts occurred repeatedly in disparate locations and times. We have stated in this article that this type of building has been found in the African, Eurasian (European and Asian) and American continents.

Once the structure of buildings with base-to-ridge posts is fully developed, it could then be inherited within and disseminated outside each region. In this article, we call this architectural tradition, being inherited and disseminated today, an active architectural heritage.

This type of architecture originated in more than one place, although details of the origins are yet to be determined. Each area where buildings with base-to-ridge posts developed must have a history of inheritance and dissemination. Taking the northern part of the Mesoamerica region as our example, we examined in this article the characteristics of inheritance and dissemination of this type of architecture.

In addition, this type of architecture is found in regions of our survey where there are different climates and even if the required materials are no longer available. This structure is resistant to hurricane winds; however, the structure is distributed not only in the hurricane-prone coastal areas, but also in desert, mountainous and snowy regions (Felger [20], [2]). We think that structures with base-to-ridge posts have been chosen in different regions around the globe because the structure is easy to construct and is resistant to different climate conditions rather than particularly suited to certain climates or materials. This being the case, it would not be accurate to call this type of buildings vernacular, as they are used in a global scale till today. The structures with base-to-ridge posts are used not only for private buildings by ordinary people, but also used for Shinto shrines in Japan [2] and for non-religious government buildings in China [10]. In this sense, too, it may not be appropriate to call this type of architecture vernacular.

\section{PRESERVATION OF TRADITION IN THE CASE OF ACTIVE ARCHITECTURAL HERITAGES}

The tradition of building with base-to-ridge posts, which we consider active architectural heritage in this article, has been maintained by non-specialist, ordinary people. Those people share common values and architectural technologies with others within the same community. If dramatic changes occur in their communities in future, the traditional value system may be 
abandoned, and as a result, the traditional technologies may disappear. Hence, for preservation of the tradition, the communities supporting the value systems of local peoples are maintained. The buildings we surveyed used both traditional materials (e.g. palm and maguey) and new, alien materials (e.g. eucalyptus). The structure with base-to-ridge posts was developed a long time ago, supposedly disseminated over long distances, and used widely around the globe even today. As such, this co-presence of traditional and new materials is a reflection of the fact that the structure with base-to ridge-posts allowed the use of different materials according to the environment and time during the dissemination process.

Each of the areas surveyed has its own tradition of plant utilization, which influences strongly the choice of construction materials. Such tradition has its basis in the communal culture of the people using buildings with base-to-ridge posts. For the better preservation of the architectural tradition of buildings with base-to-ridge posts, the technologies and materials used in traditional communities must be maintained by acknowledging the importance of the preservation of the communal culture. On the other hand, structures with base-to-ridge posts have been disseminated and, as we have shown in this article, are being disseminated till today. In this aspect of preservation through dissemination, the use of new technologies and materials should be tolerated since the tradition is to be maintained across communal boundaries.

Based on the above considerations, we claim that there are two aspects for the better preservation of the tradition of buildings with base-to-ridge posts: first, the traditional technologies and materials must be maintained by local communities; and second, the use of new technologies and materials should be tolerated when the architectural structure is disseminated across communal boundaries. The former corresponds to the central part of Fig. 7 (area of inheritance) and the latter to the surrounding areas (areas of dissemination).

This co-presence of inheritance and dissemination aspects corresponds to the fact that the indices we used in this article divide the samples largely into two categories. The inheritance
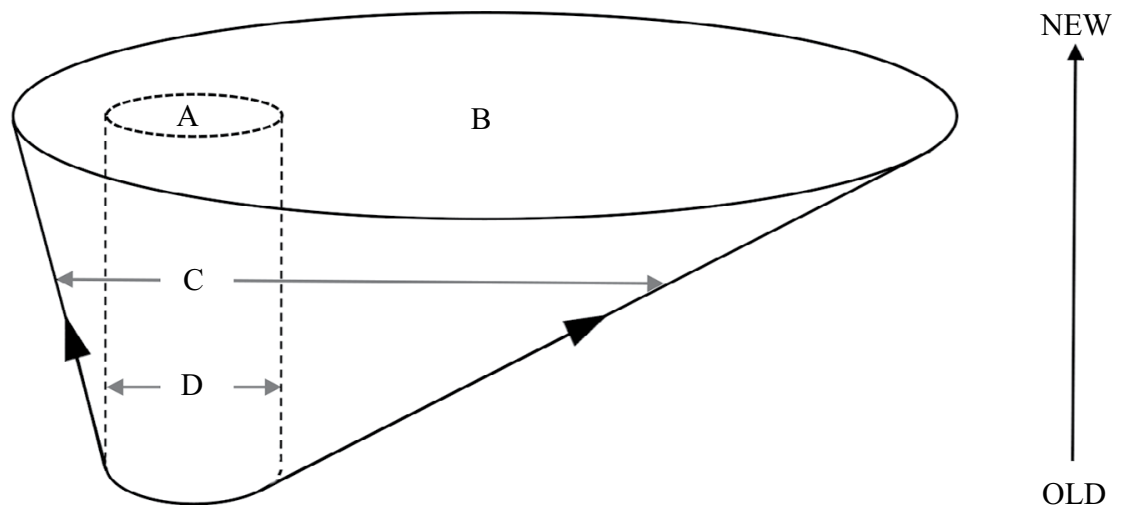
A: The areas where the tradition has been inherited (the central areas)
$\mathrm{B}$ : The areas to which it has been disseminated (surrounding areas)
C: Dissemination
D: Inheritance

Figure 7: The areas where the tradition has been inherited (the central area) and areas to which it has been disseminated (surrounding areas) 
aspect is more essential to the tradition because it secures authenticity and integrity, while the dissemination part relates to secondary factors, but the flexibility regarding those factors is essential for the active preservation of the tradition.

\section{FINAL WORDS}

The observations presented in this article indicate that the value of buildings with base-toridge posts as cultural heritage lies in the fact that the structure has been chosen and actively used by the people as part of their effective knowledge for survival, and that the inheritance/ dissemination of the structure is not so difficult, being possible without words but depending solely on visual forms. Such dissemination has been a human intellectual activity since ancient times, and as a result buildings with base-to-ridge posts are used in different regions today. Thus, we maintain that the buildings with such structure in the northern part of Mesoamerica are examples of an active architectural heritage, in which this type of buildings is inherited, disseminated and managed by real people. The buildings in actual use and surveyed for this article are part of the practical basis for the inheritance and dissemination of the heritage in the future.

\section{REFERENCES}

[1] Giancarlo, C., All' origine dell' abitare, Aline: Firenze, 1986.

[2] Tsuchimoto, T., Original Form Theory on Ridge-Supporting Post, Chuo Kouron Bijutsu Shuppan: Tokyo, 2011.

[3] Umesao, T., Housing of the Datoga (the second paragraph in chapter 4), Studies in African Society; Report of the Kyoto University Africa Scientific Expedition, ed. Imanishi, K. \& Umesao, T., Nishimura-Shyoten: Tokyo, pp. 173-180, 1968.

[4] Schilli, H., Das Schwarzwaldhaus, W. Kohlhammer: Stuttgart, 1953.

[5] Weiss, R., Häuser und Landschaften der Schweiz, Erlenbach: Eugen Rentsch: Zürich, 1959.

[6] Gschwend, M., Bauernhäuser der Schweiz, Schweizer Baudokumentation: Blauen, 1989.

[7] Ota, K., Ethno-Architecture, Kajima Institute Publishing Co.: Tokyo, 2010.

[8] Ivanov, S. V., Старинное Зимнее жилище ульчей (Ancient Winter Houseof Ul'chi) Главе 2 (Chapter 2). Сборник Музея антропологии иэтнографии том 13 (Collection of the Museum of Anthropology and Ethnography Volume 13), Институт этнографии им. Н.Н. Миклухо-Маклая АН СССР (Institute of Ethnography. NN Maclay USSR Academy of Sciences): Москва (Moscow), 1951.

[9] Wakabayashi, H., Origin of the Floor Elevated Buildings, Koubundo Publishers Inc.: Tokyo, 1986.

[10] Li, Y. \& Tsuchimoto, T., Study on Munamochi-Bashira of Post-and-Lintel construction in the traditional structures of northern China. Journal of architecture and planning (Transaction of AIJ), 78(688), pp. 1399-1408, 2013.

[11] Watanabe, H., The Northern pacific maritime culture Zone - A viewpoint from HunterGatherers I. Bulletin of the National Museum of Ethnology, 13(2), Tokyo, pp. 300-301, 1988.

[12] Wood, B., Human Evolution: A Very Short Introduction, Oxford University Press: Oxford, 2005.

[13] Koshi, E. \& Tsuchimoto, T., On Buildings with base-to-ridge posts in Mexico. Summaries of Technical Papers of Annual Meeting Architectural Institute of Japan, No. 9007 : Tokyo, pp. 13-14, 2013. 
[14] Nabokov, P. \& Easton, R., Native American Architecture, Oxford University Press: New York, 1989.

[15] Morales, F. J. L., Arquitectura Vernacula en Mexico, Trillas: México, D. F, 1993.

[16] Prieto, V., Vivienda Campesina en Mexico, Studio Beatrice Trueblood: México, 1994.

[17] Francisco, G. R., Arquitectura varnacula del sotavento, Consejo Nacional para la Cultura ylas Artes: México, D. F., 2010.

[18] Beatriz, B. C., La arquitectura de Mesoamerica y de la Gran Chichimeca, Instituto Nacionalde Antropologia e Histria: México, D. F., 2010.

[19] Schmidt, W., Der heilige Mittelpfahl des Hauses, Anthropos, Bd. 35/36, H. 4./6., Jul.Dec., pp. 966-969, 1940-1941.

[20] Felger, R.S., People of the Desert and Sea: Ethnobotany and the Seri Indians, The University of Arizona press: Tucson, 1985.

[21] Watanabe, H., Houses of hunter-gatherer Viewpoints from the north, Origin of the houses of Japan. A Study on Cultural Prototype of Japan, Bunka Publishing Bureau: Tokyo, pp. 389-417, 1984.

[22] Oliver, P., Encyclopedia of Vernacular Architecture of the World, Vol. 1-3, Cambridge University Press: Cambridge, 1997.

[23] Tanaka, T., Form of small buildings with Munamochi-bashira structure. Shinshu University Graduation Thesis, Nagano, Japan, 2014.

[24] Koshi, E. \& Tsuchimoto, T., The Importance of buildings with base-to-ridge posts in Mexico in the global history of architecture, Structural Studies. Repairs and Maintenance of Heritage Architecture XIV, WIT Press, pp. 783-795, 2015. 